\section{O modelo assistencial em saúde mental no Brasil: a trajetória da construção política de 1990 a 2004}

\author{
The mental health care model in Brazil: a history of \\ policy development from 1990 to 2004
}

\begin{abstract}
This article analyzes the underlying conditions in the development of Brazil's national policy for mental health care from 1990 to 2004, with the aim of identifying the priorities in each historical stage of the policy, based on a review and analysis of rulings and other official documents issued by the Ministry of Health during this period. Four stages in the mental health care policy are discussed, the seminal period, latency, resumption, and expansion, seeking to identify the principal policy guidelines and their correlations with the overall context of the Unified National Health System (SUS). Finally, the article provides an overview of the mental health care model developed under this policy, comparing it to the Basaglian theoretical and ideological framework, the reference adopted by the Brazilian psychiatric reform movement, and suggesting elements for reflection on the work of the National Division of Mental Health.
\end{abstract}

Mental Health; Health Policy; Health Care Reform
Camila Furlanetti Borges 1

Tatiana Wargas de Faria Baptista 1

\section{Introdução}

Falar em políticas de saúde mental no Brasil é uma possibilidade recente, conquistada a partir do processo de reforma psiquiátrica. A assistência psiquiátrica brasileira surgiu da função saneadora dos primeiros hospícios, assumindo um papel excludente, sem fazer-se acompanhar dos psiquiatras ${ }^{1}$. É em 1890 que é criada sob administração pública a Assistência Médico-Legal aos Alienados, de caráter predominantemente asilar 2 .

Nos anos 1960, inicia-se o debate sobre a necessidade de mudanças na assistência e a incorporação de propostas desenvolvidas na Europa, como a psiquiatria preventiva e comunitária expandindo serviços intermediários; e as comunidades terapêuticas - buscando a humanização dos hospitais 3 .

Só em 1978 começa a ser constituído o movimento de reforma psiquiátrica brasileiro, ganhando expressão o Movimento dos Trabalhadores de Saúde Mental (MTSM), que num primeiro momento incorpora críticas ao hospitalocentrismo, às más condições de trabalho e de tratamento e à privatização da assistência psiquiátrica, marcando sua entrada no aparelho público ${ }^{3}$.

Em aliança com o Centro Brasileiro de Estudos em Saúde (CEBES), articulador político-ideológico da reforma sanitária, o MTSM fortaleceu seu discurso técnico e desenvolveu sua postura política. No final da década de 1980, ocorre uma 
inflexão em sua trajetória com a incorporação da noção de desinstitucionalização na tradição Basagliana ${ }^{3}$, ou seja, uma ruptura com o paradigma psiquiátrico, denunciando seu fracasso em agir na cura, sua aparente neutralidade científica, sua função normalizadora e excludente, e a irrecuperabilidade do hospital como dispositivo assistencial 4. O MTSM passa a apostar na desconstrução da instituição manicômio, entendida como todo aparato disciplinar, institucional, ideológico, técnico, jurídico etc., que lhe confere sustentação, e em 1987, adota o lema "por uma sociedade sem manicômios", que alimenta novas propostas de cuidado na I Conferência Nacional de Saúde Mental (I CNSM).

Das importantes experiências desenvolvidas nesse processo, uma delas ganha destaque pela aproximação com a experiência Basagliana: em 1989 o Município de Santos, São Paulo, implanta uma rede essencialmente pública de atenção territorial, de caráter substitutivo ao hospital e composto de uma estrutura complexa, capaz de responder a qualquer tipo de demanda psiquiátrico-psicológica e de caráter social. No mesmo ano é apresentado pelo Dep. Paulo Delgado, o Projeto de Lei $n^{o}$. 3.657/89, dispondo "sobre a extinção progressiva dos manicômios e sua substituição por outros recursos assistenciais $e$ regulamentava a internação psiquiátrica compulsória".

Num contexto de rediscussão do papel do Estado na saúde, de redemocratização e de desenvolvimento dos ideais da reforma sanitária, a Constituição Federal, de 1988, institui o Sistema Único de Saúde (SUS) com seus princípios - universalização, integralidade, descentralização e participação popular, e seu processo de implementação inicia-se com as Leis $n^{o}$. 8.080/90 e $n^{o}$. 8.142/90. Criam-se condições de possibilidade para a instituição no Ministério da Saúde, em 1991, da Coordenação Nacional de Saúde Mental, instância inédita no Brasil, responsável pela formulação e implementação política na área.

Tais inflexões - a criação dessa coordenação e a institucionalização do SUS - são o ponto de partida desta análise, cujo objetivo é traçar a trajetória de construção da política nacional de saúde mental no período de 1990 a 2004 e identificar as linhas de atuação priorizadas em cada momento - nomeados momento germinativo, de latência, de retomada e de expansão, e a construção do modelo assistencial.

\section{Metodologia}

Este estudo realizou uma revisão dos documentos normativos (Portarias) expedidos pelo Minis- tério da Saúde relativos à política de saúde mental no período de 1990 a 2004 a partir da consulta sistemática ao Diário Oficial da União (Seção I e eventualmente Seção II por referência de outra Portaria), onde também se identificou a edição de Resoluções do Conselho Nacional de Saúde (CNS) e Decretos.

Parte-se do pressuposto de que a análise dos documentos oferece subsídios para compreensão do modelo assistencial que a política de saúde mental logrou implementar nesses anos, entendendo que essas normativas têm o poder de desenhar limites, na medida em que abrem algumas possibilidades e fecham outras, indicando um caminho a ser seguido. Por outro lado, esse exame compõe parte de uma pesquisa que envolve ainda o estudo de documentos de outra ordem, como diretrizes políticas, manuais, declarações, relatórios etc., além de contemplar o uso de entrevistas com atores privilegiados na construção dessa política (ex-coordenadores nacionais de saúde mental e técnicos do Ministério da Saúde). Também importante foi o estudo de documentos e produções bibliográficas sobre a construção do SUS, conformando o "ambiente" de análise.

A perspectiva deste estudo privilegia o gestor federal. A despeito do consenso da necessidade de transformar o trabalho em saúde mental em um processo cada vez mais local, participativo, democrático e coerente com as construções políticas, históricas e culturais da população e do território, entende-se que uma Coordenação Nacional de Saúde Mental tem papel crucial na construção da reforma psiquiátrica. Essa instância deve criar condições para implementação, em nível local, daquilo que crê ser o modelo de cuidado mais adequado à saúde mental. Sob a produção normativa, existe uma sustentação política, jurídica e teórico-conceitual que dá o tom da reforma psiquiátrica em curso.

Foram colhidas portarias de 1990 a 2004, recorte que se justifica dado o momento de início da política de saúde mental e de implementação do SUS. Esses documentos têm sido expedidos pelo gabinete do ministro ou pela Secretaria de Atenção à Saúde (SAS), conforme seu conteúdo e implicação financeira. A maioria deles foi elaborada pela Coordenação Nacional de Saúde Mental. Ressalte-se que essas estruturas, tanto a coordenação quanto a SAS, sofreram importantes transformações lógico-estruturais no interior do Ministério da Saúde neste período, o que tem implicação direta tanto no processo de construção de documentos quanto no tipo de conteúdo a ser trabalhado. 


\section{As bases de uma política nascente}

Em 1991 a Coordenação Nacional de Saúde Mental e a Organização Pan-Americana da Saúde (OPAS) patrocinaram um encontro com objetivo de construir um documento/instrumento de referência para a política a ser adotada no Brasil e para o trabalho cotidiano na área 5. A política de saúde mental do Ministério da Saúde então divulgada apresentava a necessidade de superar uma assistência de má qualidade, custosa financeira e socialmente, superando o modelo iatrogênico através da diversificação dos recursos terapêuticos com financiamento dos mesmos e "equacionamento da questão 'saúde mental' como problema do município” 5 (p. 216). Declarava-se a aposta na descentralização como potencializadora de novas relações políticas e culturais.

Foi salientada a questão do resgate da cidadania, e em apoio ao Projeto de Lei $n^{\circ}$. 3.657/89, do Dep. Paulo Delgado, buscava-se desvincular a internação da interdição civil, além de possibilitar ao portador de transtorno mental a participação na condução de seu tratamento e uma vida ativa.

Esse encontro foi marcado pela articulação das propostas Basaglianas com os princípios da Declaração de Caracas, que pede a retirada do hospital de seu papel hegemônico, a reestruturação da assistência ligada ao atendimento em nível primário, o respeito aos direitos humanos dos portadores de transtornos mentais, a formação de recursos humanos voltada para o atendimento comunitário e a revisão da legislação dos países.

Essa articulação abria possibilidade de dubiedade da ação que passaria a ser desenvolvida pela Coordenação Nacional de Saúde Mental. Os pressupostos que embasam cada vertente apresentam incongruências que, se num primeiro momento passam despercebidas, brevemente ganham materialidade em torno de questões como: o conceito de Atenção Primária em Saúde em contraposição ao de Atenção Básica e seus efeitos sobre a responsabilização territorial com a organização de múltiplos e complexos dispositivos de assistência; a participação do Estado e seu envolvimento com a comunidade na produção de saúde; e a lógica que informa a proposta de descentralização que pode servir tanto a propósitos normatizadores, ligados a uma racionalização econômica e administrativa, ou a propósitos de caráter político, voltados para a participação da sociedade nos processos locais potencialmente promotores da desinstitucionalização. Ademais, a Declaração de Caracas não toca no aspecto da desconstrução do saber psiquiátrico que está no cerne das experiências vividas em Trieste (na Itália) e em Santos (Estado de São Paulo, Brasil).

Em suma, esse é um contexto de efervescência teórico-ideológica em torno do direcionamento da reforma psiquiátrica brasileira, e no que tange ao sistema de saúde, o momento é de regulamentação e implementação das leis que regem o SUS. Sua organização é marcada pela diretriz da descentralização, que tem sido coordenada pelas Normas Operacionais Básicas (NOBs) desde 1991, e seu conteúdo, voltado preferencialmente para os aspectos de financiamento e prestação de serviços, impactam na construção do modelo assistencial em saúde mental.

Entendido o contexto no qual tem início a política brasileira de saúde mental, podemos apresentar uma breve análise dessa produção.

\section{A política de saúde mental na década expandida (1990 a 2004)}

A produção normativa está organizada temporalmente em quatro momentos - germinativo, de latência, de retomada e de expansão - com características específicas e duração variada. Em cada um são explicitados os principais elementos que norteiam a ação política, buscando correlação com o contexto mais geral do SUS bem como com os argumentos que a princípio respaldavam o movimento de reforma psiquiátrica.

\section{Momento germinativo: 1990 a 1996}

O ano de 1990 vivencia a extinção da Divisão Nacional de Saúde Mental (DINSAM), responsável pela Campanha Nacional de Saúde Mental e pelo pagamento de alguns hospitais psiquiátricos públicos, mas sem atuação de proposição ${ }^{6}$. Em 1991 é criada a Coordenação Nacional de Saúde Mental, tendo como primeiro coordenador um funcionário de carreira do Ministério da Saúde e militante da reforma psiquiátrica. O coordenador permanece no cargo durante cinco anos, atravessando cinco mandatos ministeriais com forte articulação política tanto internamente quanto externamente ao Ministério da Saúde, mas principalmente com gestores de outros níveis de governo, quando é organizado o Colegiado dos Coordenadores Estaduais.

Configura-se nesse período da política nacional de saúde mental o que denominamos o momento germinativo. Primeiro, porque é a partir deste que há uma grande articulação de atores na discussão dessa política, com a constituição de grupos de trabalho diferenciados, parcerias formais e informais, diálogo com consultores etc. - o que se expressa com a realização da II CNSM. 
Segundo, pela ascensão de debates e audiências promovidas em torno do Projeto de Lei $n^{o}$. 3.657/89, possibilitando a explicitação de personagens e grupos de interesse e o desenvolvimento de propostas de atuação política.

O caráter germinativo também é atribuído à atuação da coordenação na organização da assistência hospitalar, com o viés da desospitalização, fundamentada em ações de avaliação e acreditação hospitalar. O primeiro documento normativo nesse sentido foi editado em 1991: a Portaria SNAS $n^{\circ} .189 / 91$ (Tabela 1), normatizava grupos de procedimentos do Sistema de Informações Hospitalares (SIH) e do Sistema de Informações Ambulatoriais (SIA) possibilitando o custeio de ações e serviços alternativos 6 .

Seu ponto forte é a alteração do financiamento, mas estão presentes também a especificação de rotinas e os prazos para apresentação de Autorização de Internação Hospitalar (AIH), bem como normatização para internações e hospital-dia. Essa Portaria desdobra-se em quatro linhas de atuação que terão prosseguimento diferenciado nos documentos normativos seguintes: (1) qualificação/desospitalização; (2) avaliação; (3) Autorização de Internação Hospitalar (AIH); (4) Centros de Atenção Psicossocial (CAPS) e SIA.

\section{- Qualificação/Desospitalização}

Essa linha de atuação é composta das Portarias voltadas para organização de grupos e procedimentos do SIH, referente aos serviços hospitalares e de hospital-dia. Em seqüência ao item 1 da Portaria germinativa (Portaria SNAS no. 189/91), as outras editadas nos anos de 1992 a 1996 organizam a classificação das unidades hospitalares com vistas a um processo de acreditação com prazos e sanções estabelecidos. O objetivo é melhorar as condições hospitalares e ao mesmo tempo induzir a desospitalização, na medida em que, não atendidos os prazos, as unidades são descredenciadas. Para os acreditados é previsto reajuste de pagamento diferenciado. Dezoito Portarias compõem a linha de atuação durante esse período (Tabela 1).

\section{- Avaliação}

Apenas duas Portarias compõem esta linha de atuação, e, apesar de a primeira ter sido publicada apenas em 1993 (Portaria SAS no. 63/93; Tabela 1), a avaliação é um processo que subsidia a qualificação e a desospitalização, enfocando a correta aplicação das normas dessa linha de atuação. Neste momento, a avaliação era feita por um grupo de composição multiprofissional e de diversos níveis de gestão, bem como por representantes de diferentes entidades interessadas. A segunda Portaria desta linha (Portaria $S A S n^{\circ}$. 145/94) indica a criação do grupo de avaliação nas três esferas de governo, e possibilita a inspeção de unidades do SIA ou do SIH, mas prioriza os hospitais, que são selecionados via sorteio, denúncias ou solicitações, e atribui as atividades de elaboração de formulário de indicadores e de relatórios, e aplicação das sanções previstas.

\section{- Autorização de Internação Hospitalar (AIH)}

Essa linha de atuação também tem origem na Portaria SNAS $n^{\circ}$. 189/91, tendo gerado mais duas: Portaria SAS $n^{\circ}$. 22/94 e Portaria SAS $n^{\circ}$. 119/96. Visa à regulamentação da sistemática de pagamento de AIH, determinando sobre duração de internação e prazos. Este é um ramo menos expressivo, mas que traz implicações importantes para o manejo das internações, e, como a avaliação, é diretamente relacionada com o processo de qualificação e desospitalização.

Ilustrativa é a ocorrência de portarias que se enquadram simultaneamente em mais de uma dessas três linhas de atuação, ilustrando tanto o potencial germinativo quanto o fato de comporem um bloco único e indissociável referido ao sistema hospitalar.

\section{- Centros de Atenção Psicossocial (CAPS) e} Sistema de Informações Ambulatoriais (SIA)

Linha que visa à organização de grupos e procedimentos do SIA, incluindo atendimento em CAPS e Núcleos de Atenção Psicossocial (NAPS), atendimento em oficinas terapêuticas e em grupo, visita domiciliar e psicodiagnóstico, abarcando ações e serviços para conformação de um modelo assistencial de base comunitária. Apenas duas portarias compõem este ramo: Portaria SNAS $n^{o}$. 189/91 e Portaria SNAS $n^{o}$. 224/92. O pequeno desdobramento desta linhagem neste momento pode ser atribuído a alguns fatores: primeiro, o SUS ainda não dispunha de recursos significativos para a implantação de novas unidades, garantindo apenas custeio. As NOBs de 1991 e 1993, que entre outras coisas normatizam a descentralização financeira do SUS, são expedidas em contexto de arrocho financeiro, e apenas a partir de 1994 logram construir condições de gestão e de repasse de recursos que, segundo as prioridades municipais e/ou estaduais, podem ser usados na construção de novas unidades. Nesse caso, a construção de CAPS fica na dependência de sua entrada na agenda do gestor local. Segundo, neste momento o debate 
Tabela 1

Portarias que compõem as linhas de atuação no período 1991 a 2004

\begin{tabular}{|c|c|c|c|c|c|c|}
\hline \multirow[t]{2}{*}{ Ano } & \multicolumn{6}{|c|}{ Linhas de atuação } \\
\hline & $\begin{array}{l}\text { Qualificação/ } \\
\text { Desospitalização }\end{array}$ & $\begin{array}{c}\text { Avaliação/ } \\
\text { Desospitalização * }\end{array}$ & AlH & CAPS & $\begin{array}{l}\text { Programa De } \\
\text { Volta para Casa }\end{array}$ & $\begin{array}{l}\text { Serviço residencial } \\
\text { terapêutico }\end{array}$ \\
\hline 1991 & Portaria SNAS n. 189 ** & & $\begin{array}{c}\text { Portaria SNAS } \\
n^{\circ} .189 * \star\end{array}$ & $\begin{array}{c}\text { Portaria SNAS } \\
n^{\circ} .189 \text { ** }\end{array}$ & & \\
\hline 1992 & $\begin{array}{c}\text { Portarias: SNAS n. } 224 \text { **; } \\
\text { SNAS n. } 247 ; \text { SAS n. } 407 ; \\
\text { SAS n. } 408\end{array}$ & & & $\begin{array}{c}\text { Portaria SNAS } \\
n^{\circ} .224^{\star \star}\end{array}$ & & \\
\hline 1993 & $\begin{array}{l}\text { Portarias: SAS n. } 47 \\
\text { SAS n. } 88 ; \text { SAS n. } 180\end{array}$ & Portaria SAS nº. 63 & & & & \\
\hline 1994 & 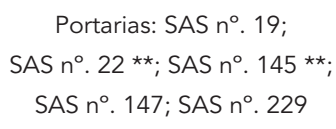 & $\begin{array}{c}\text { Portaria SAS } \\
n^{\circ} .145^{\star *}\end{array}$ & $\begin{array}{c}\text { Portaria SAS } \\
n^{\circ} .22 \text { ** }\end{array}$ & & & \\
\hline 1995 & $\begin{array}{l}\text { Portarias: SAS n. } 66 \\
\text { SAS n. } 93 ; \text { SAS n. } 94\end{array}$ & & & & & \\
\hline 1996 & $\begin{array}{l}\text { Portarias: SAS n०. } 15 \\
\text { SAS } n^{\circ} .193\end{array}$ & & Portaria SAS nº 119 & & & \\
\hline 2000 & & $\begin{array}{l}\text { Portarias: } \mathrm{GM} \mathrm{n}^{\circ} .799 ; \\
\text { SAS n. } 306\end{array}$ & & & & $\begin{array}{l}\text { Portarias: } \mathrm{GM} n^{\circ} .106 ; \\
\text { GM n. } 1.220\end{array}$ \\
\hline 2001 & & Portaria GM n. 469 ** & $\begin{array}{l}\text { Portarias: SAS } n^{\circ} .111 ; \\
\qquad G M n^{\circ} .469^{* \star}\end{array}$ & & & Portaria GM n. 175 \\
\hline 2002 & & $\begin{array}{l}\text { Portarias: } G M n^{\circ} .251 \text { **; } \\
\text { SAS n. } 77 ; \\
\text { GM n. } 1.467 ; \\
\text { SAS n०. } 1.001\end{array}$ & & $\begin{array}{c}\text { Portarias: } \mathrm{GM} \mathrm{n} \text { ․ } 336 ; \\
\text { SAS n. } 189 ; \\
\text { GM n. 626; GM n. } 816 ; \\
\text { GM n. 817; SAS n. } 305\end{array}$ & & \\
\hline 2003 & & Portaria SAS n. 150 & & 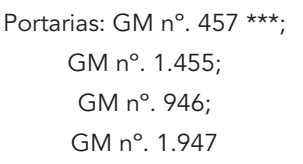 & $\begin{array}{c}\text { Lei } \mathrm{n}^{\circ} .10 .708^{\star \star \star} \\
\text { Portarias: } \mathrm{GM} \\
\mathrm{n}^{\circ} .2 .077 \\
\mathrm{GM} \mathrm{n} \mathrm{n}^{\circ} .2078\end{array}$ & \\
\hline 2004 & & $\begin{array}{l}\text { Portarias: } \mathrm{GM} \mathrm{n} \mathrm{n}^{\circ} .52 \\
\mathrm{GM} \mathrm{n}^{\circ} .53\end{array}$ & & & & \\
\hline Total & 18 & 12 & 5 & 12 & 2 & 3 \\
\hline
\end{tabular}

AlH: Autorização de Internação Hospitalar; CAPS: Centros de Atenção Psicossocial.

Fonte: Elaboração própria a partir das Portarias ministeriais (1990-2004).

Nota: nos anos 1997 e 1998 não foram editadas Portarias de saúde mental e no ano de 1999 apenas uma Portaria versou sobre a área (Portaria GM n. 1.077) retratando o programa para aquisição de medicamentos essenciais, consoante à política do Ministério da Saúde, mas não implicada necessariamente com a reforma psiquiátrica.

* As Portarias de avaliação retomam a tônica da desospitalização a partir de 2000;

** Portarias que se enquadram em mais de uma linha de atuação. Isso ilustra tanto o que estamos chamando de potencial germinativo (caso das Portarias SNAS n. 189/91 e SNAS n. 224/92), ou, em alguns casos, o enredar-se entre duas linhas de atuação (caso das Portarias SAS n. 22/94 e SAS n. 145/94).

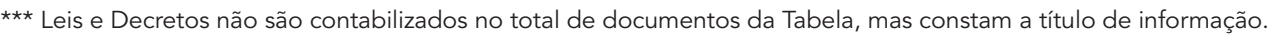


político acirrava-se em torno do Projeto de Lei $n^{o}$. 3.657/89, direcionando esforços para as tensões relacionadas ao setor hospitalar.

Acompanhando o cenário de produção normativa constata-se o avanço no processo de desospitalização, que contou ainda com o descadastramento de leitos de cobrança que não existiam de fato (Figura 1), enquanto a expansão dos CAPS não encontrou seu momento mais forte (Figura 2).

Ressalte-se o potencial germinativo da produção normativa de 1991 a 1996, pois, apesar de não haver configurado um desenho de modelo assistencial que vislumbrasse o que o movimento pela reforma psiquiátrica ansiava, ou seja, uma rede de serviços de complexidade e territorializada tal qual aquela composta em Trieste ou em Santos, preparava terreno para a construção de uma rede ampla através do enfrentamento da questão da desospitalização e da abertura do financiamento, bem como através da construção de consensos e de legitimidade em torno da política de saúde mental.

Em meados de 1996 o então coordenador deixa o cargo, e logo em seguida ocorre mudança de Ministro da Saúde.

\section{Momento de latência: 1997 a 1999}

Neste período a coordenação foi assumida pelo vice do coordenador anterior. Importava manter no cargo uma pessoa afinada com a estratégia desenvolvida até então. O novo Ministro da Saúde entraria com um perfil de atuação voltada para harmonização com as teses econômicas do governo e efetuou mudanças na estrutura do Ministério da Saúde que repercutiram na condução política da saúde mental. Em 1997 foi instituída a Secretaria de Políticas de Saúde (SPS), responsável pela coordenação da formulação política e da avaliação no âmbito do SUS 7 . Essa mudança levou a um enfraquecimento da SAS, que abrigava a Coordenação Nacional de Saúde Mental. E esta foi desarticulada enquanto estrutura de formulação política, sendo alocada na SPS com um caráter mais consultivo que propositivo, e sem poder de articulação interna ou externa.

Com isso, os anos de 1997 e 1998 são vazios de Portarias. É ilustrativa a Resolução $n^{o} .272 / 98$ do CNS que propõe "criar a comissão visando estabelecer interlocução com o Ministério da Saúde para análise dos fatores que têm determinado o não cumprimento adequado das metas e estraté-

Figura 1

Leitos psiquiátricos do Sistema Único de Saúde (SUS) por ano. Brasil, 1990 a 2003.

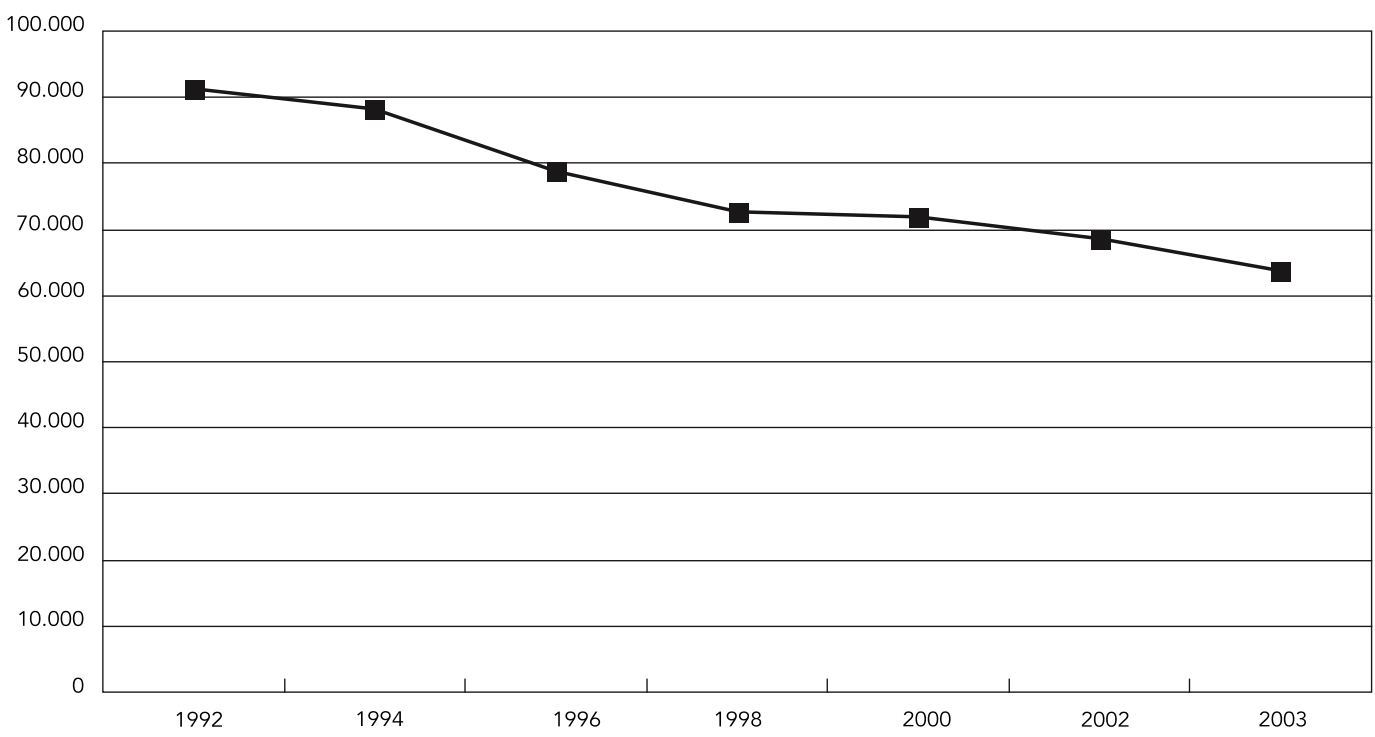

Fonte: Sistema de Informações Hospitalares (SIH), http://tabnet.datasus.gov.br/cgi/tabcgi.exe?sih/cnv/cxuf.def (acessado em 04/Dez/2006). 
Figura 2

Expansão da rede de Centros de Atenção Psicossocial (CAPS). Brasil, 1980 a julho de 2006.

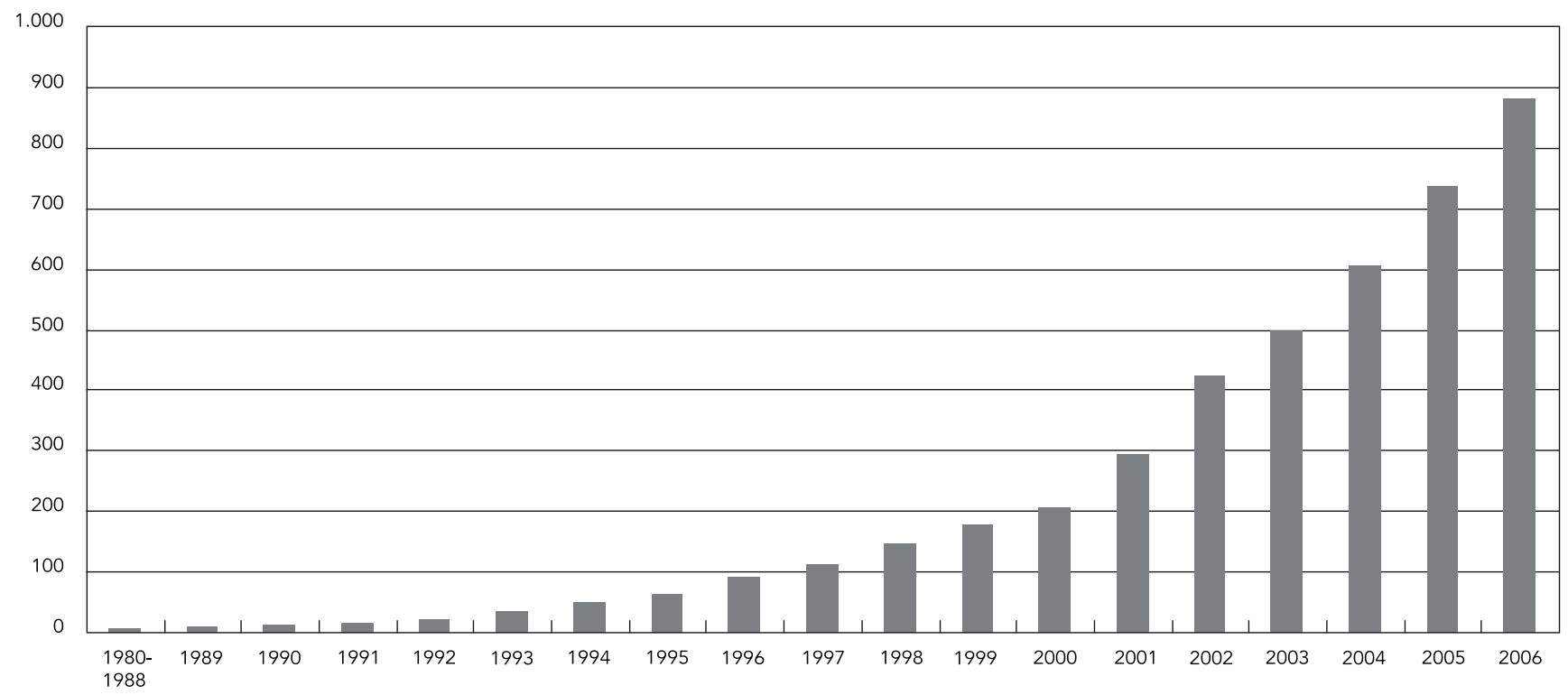

Fonte: Coordenação de Saúde Mental, Secretaria de Atenção à Saúde, Ministério da Saúde; http://www.inverso.org.br/index.php/content/view/14386.htm (acessado em 04/Dez/2006).

gias da reforma psiquiátrica uma vez que o próprio conselho já havia se pronunciado sobre a matéria" 8. Desde a criação da Comissão Nacional de Reforma Psiquiátrica (CNRP) do CNS, este tem se mostrado um importante interlocutor tanto na articulação de interesses quanto na formulação de propostas e na cobrança de ações na área.

Em 1999 é publicada apenas uma Portaria, que não chega a promover uma linha de atuação: a $G M n^{o} .1 .077 / 996$ (Tabela 1). Esta implanta o Programa para Aquisição dos Medicamentos Essenciais para a Área de Saúde Mental e constitui um grupo técnico-assessor para avaliar o impacto na reestruturação do modelo de atenção. Também é promulgada a Lei $n^{\circ}$. 9.867/99, que cria as Cooperativas Sociais, beneficiando inclusive a clientela psiquiátrica 6 .

É provável que essa breve produção em 1999 se deva à entrada, no ano anterior, quando também há mudança de Ministro da Saúde, do novo coordenador da política de saúde mental, também militante da reforma psiquiátrica. No entanto, mantinha-se a estrutura ministerial que pouco privilegiava o andamento do que estava sendo construído anteriormente. Por outro lado, o CNS mostra-se atuante, produzindo Resoluções coe- rentes com o projeto do movimento da reforma psiquiátrica. Por essa queda de produção normativa, pelo fato de o cargo de coordenador ter se mantido nas mãos de militantes da reforma psiquiátrica, e pela manutenção de propostas compatíveis por parte do CNS é que chamamos este de momento de latência, quando a coerência interna da condução política é subentendida.

\section{Momento de retomada: 2000 a 2001}

Em 2000, nova estrutura ministerial é adotada, e as coordenações de áreas técnicas, como a de saúde mental, voltam para a SAS, significando o retorno a um ambiente propício à alavancagem da política da área.

Ainda como fruto da coordenação assumida em 1998, é publicada a $G M n^{\circ}$. 106/00, que cria a linha de atuação dos Serviços Residenciais Terapêuticos, proposta que se encontrava em maturação desde o início da Coordenação Nacional de Saúde Mental, contando com o CNS para não deixar ficar apenas como idéia, e objetiva tornar mais exeqüível a desospitalização de pacientes que passaram por longas internações. É possível discutir se esse serviço seria uma modalidade 
assistencial e terapêutica, ou se se trata de uma estratégia de fortalecimento do modelo assistencial.

Desde 1999, denúncias de maus tratos e negligência em hospitais psiquiátricos foram ganhando espaço na mídia levando a forte comoção da sociedade. Uma questão de tamanha visibilidade, cobrada por um movimento social atuante, requeria uma resposta urgente do Ministério da Saúde, que foi a publicação da GM $n^{\circ}$. 799/00, que retoma a linha de atuação da desospitalização com uma outra conotação, mais próxima da avaliação ${ }^{6}$. Produzida no curto intervalo entre a entrada de um coordenador e a saída de outro, essa portaria instituiu o Programa Permanente de Organização e Acompanhamento das Ações Assistenciais em Saúde Mental. A composição do grupo de avaliação conta com um representante da Comissão de Direitos Humanos da Câmara dos Deputados, que neste ano realizou a I Caravana Nacional de Direitos Humanos, percorrendo os hospitais psiquiátricos do país, e retomou a discussão do Projeto de Lei da reforma psiquiátrica. Não foi estabelecida avaliação sistemática que englobasse todas as unidades do SUS, mas respondeu a uma situação emergencial.

Neste ano 2000, um novo Coordenador de Saúde Mental - que permanece no cargo até os dias atuais, militante da reforma psiquiátrica e do Partido dos Trabalhadores (PT), e envolvido com a formulação do Projeto de Lei $n^{o}$. 3.657/89, assume o cargo num contexto da gestão ministerial e do governo do Partido da Social Democracia Brasileira (PSDB). Isso ilustra que a escolha do novo coordenador é norteada principalmente pelo seu perfil técnico e pelo seu envolvimento histórico com os movimentos sociais que embasam a reforma psiquiátrica brasileira. Isso nos permite chegar a esse momento afirmando que desde o nascimento da política de saúde mental, sua coordenação não tem sofrido intempéries de outros critérios de nomeação que não aqueles de um alinhamento com o movimento informante da reforma psiquiátrica. Se os ideais deste movimento ainda não gozam do status de hegemônico, por outro lado conseguiram firmar sua legitimidade na sociedade e no aparelho público.

A primeira portaria dessa coordenação, GM $n^{o} .1 .220 / 00$, faz a inclusão na tabela SIA do Serviço Residencial Terapêutico e do código para cuidador em saúde, sendo a segunda portaria dessa linha de atuação que será seguida por apenas mais uma em 2001: GM no. 175/01 6. Esse dispositivo assistencial inaugura, para a saúde mental, o uso do Fundo de Ações Estratégicas e de Compensação (FAEC). Criado a partir de algumas alterações da NOB de 1996, o FAEC é parte da estratégia do Ministério da Saúde de arregimentar maior fonte de recursos e tem sido empregado em ações de indução de modelo assistencial 7,9.

Duas portarias em 2001 retomam a linha de atuação da AIH: SAS no. 111/01 e GM $n^{o} .469 / 01$ (Tabela 1). Esta segunda foi gestada fora da Coordenação Nacional de Saúde Mental e propõe um mecanismo de classificação hospitalar perverso de acordo com a quantidade de internação paciente/mês. Com um discurso de otimização do aparato hospitalar, quanto maior a quantidade de AIH emitidas, maior a remuneração. A coordenação logra revogá-la com a GM n ${ }^{\circ}$. 251/02.

O ano de 2001 é marcado por dois eventos cruciais para a política de saúde mental: a aprovação, em abril, da Lei $n^{\circ}$. 10.216 6, a lei da reforma psiquiátrica; e a realização da III CNSM, com ampla participação e a elaboração de um relatório final extenso, com propostas variadas, às vezes conflitantes, mas certamente voltadas entre outras coisas para inovação do modelo assistencial e expansão da rede de serviços alternativos. Esse processo deixa marca através das portarias produzidas no momento seguinte: a maioria delas tem ligação direta com o relatório da III CNSM ou com seminários que passaram a ser mais freqüentemente organizados pela Coordenação Nacional de Saúde Mental.

Em suma, justifica a nomeação deste como momento de retomada: a entrada do novo coordenador, o retorno da Coordenação Nacional de Saúde Mental à SAS, a aprovação da Lei $n^{\circ} .10 .216$ e a realização da III CNSM, e a retomada propositiva com a inauguração de uma nova linha de atuação - Serviços Residenciais Terapêuticos - e a recuperação de outras - avaliação e AIH.

\section{Momento de expansão: 2002 a 2004}

Esse momento expande o desenho de um modelo assistencial diversificando suas linhas de atuação: (1) avaliação/desospitalização; (2) Programa De Volta para Casa; (3) CAPS.

\section{- Avaliação/Desospitalização}

Essa linha foi retomada com a GM $n^{o}$. 799/00 (Tabela 1), portando uma inflexão - o processo de qualificação perdeu peso em relação ao de avaliação dos serviços hospitalares, por isso a recomposição da linha de atuação. Fica cada vez mais explícita a política de redução do porte hospitalar, culminando com o Programa Anual de Reestruturação da Assistência Psiquiátrica Hospitalar no SUS, apresentado em 2004 (GM $\left.n^{o} .52 / 04\right)$. Desde a $G M n^{o} .251 / 02$, o processo de avaliação torna-se significativamente diferenciado do que era realizado até então com a entrada do Programa Nacional de Avaliação dos Serviços 
Hospitalares (PNASH-Psiquiatria), de cunho mais técnico e com vistorias mais regulares. Essa linha é representada por nove Portarias (Tabela 1).

\section{- Programa De Volta Para Casa}

Apesar de ganhar oficialidade apenas em 2003, essa linha de atuação já vinha sendo maturada, ora pela Coordenação Nacional de Saúde Mental, ora pelo CNS, ora nos espaços de conferências e seminários, desde o início da década de 1990. Esse ramo normatiza o Auxílio-Reabilitação Psicossocial, que além de tornar mais exeqüível a desospitalização de pessoas que passaram por internações longas e não dispõem de trabalho ou outra fonte de renda, é um facilitador no processo de inserção social. A construção desse grupo de Portarias foi possível mediante alteração no reconhecimento civil dos portadores de transtornos mentais e instituição do Auxílio-Reabilitação Psicossocial pela Lei $^{\circ}$. 10.708/03. A aprovação da Lei $n^{\circ}$. 10.216/01 e a III CNSM foram decisivas no desengavetar dessa proposta. Não se trata de um dispositivo assistencial propriamente dito, mas de um dispositivo que vem fortalecer os demais recursos do modelo assistencial. A produção de Portarias dessa linha é pontual e concentrada, contando com apenas duas (Tabela 1).

\section{- Centros de Atenção Psicossocial (CAPS)}

Linha de atuação diretamente sensível à III CNSM, que tirou a recomendação de nova regulamentação e ênfase na expansão dessa modalidade assistencial. Os procedimentos do CAPS passam a ser remunerados de acordo com a freqüência dos usuários, e cria-se a classificação em CAPS I, II ou III de acordo com a abrangência populacional. Mais uma vez a área da saúde mental é contemplada com recursos do FAEC o que contribuiu sobremaneira para a expansão da rede, já que houve verba para implantar novas unidades, para fazer o custeio dos procedimentos extra-teto e para alguns programas de formação/capacitação. Surgiram os Centros de Atenção Psicossocial Infantil (CAPSi), voltados para crianças e adolescentes, e os Centros de Atenção Psicossocial para Álcool e Outras Drogas (CAPSad), voltados para pacientes com transtornos decorrentes do uso e dependência de substâncias psicoativas. Todos os tipos de CAPS encontram uma normatização comum nas Portarias $G M n^{\circ} .336$ e $S A S n^{\circ} .189$, ambas de 2002. Neste ano e em 2003 são produzidas mais oito normativas, mas o desdobramento desta linha de atuação configura um total de três destinadas aos CAPSi, quatro aos CAPSad e duas aos CAPS I, II e III, conforme expresso na Tabela 2.

O FAEC, pela expansão de seu montante desde 2001, pôde incorporar novas ações programáticas e expandir políticas mais específicas no bojo da nova tipologia dos CAPS. Com isso foi possível, em 2003, passar a tratar a política de saúde voltada para usuários de álcool e outras drogas como uma política e não como um programa. Além disso, a Norma Operacional da Assistência à Saúde (NOAS) 01/01 induz um enfoque na abrangência populacional, e as portarias de incentivos para CAPS apresentam planos de expansão que contemplam municípios de grande porte.

Apesar de não formarem uma linha de atuação, outras normas importantes foram publicadas neste momento de expansão. A GM $n^{o}$. 2.391/02 regulamenta a Lei da reforma psiquiátrica no que diz respeito ao tratamento das internações voluntárias e involuntárias e os procedimentos de notificação ao Ministério Público 6.

Desdobramento da linha de atuação Centros de Atenção Psicossocial (CAPS) no período 2002 a 2003.

\begin{tabular}{|c|c|c|c|}
\hline Ano & CAPS & CAPSi & CAPSad \\
\hline 2002 & $\begin{array}{c}\text { Portarias: } \mathrm{GM} n^{\circ} .336 * \text {; SAS n. } 189 * ; \\
\text { GM n. } 626\end{array}$ & Portarias: $\mathrm{GM} \mathrm{n}^{\circ} .336$ *; SAS n. 189 * & $\begin{array}{l}\text { Portarias: } \mathrm{GM} n^{\circ} .336 \text { *; SAS n. } 189 \text { *; } \\
\text { GM n. 816; GM n. 817; SAS n. } 305\end{array}$ \\
\hline 2003 & Portaria GM no. 1.455 & Portarias: GM n. 1.455; GM n. 1.946; GM n. 1.947 & Portaria GM nº. 457 ** \\
\hline Total & 4 & 5 & 6 \\
\hline
\end{tabular}

CAPSi: Centro de Atenção Psicossocial Infantil; CAPSad: Centro de Atenção Psicossocial para Álcool e Outras Drogas.

Fonte: Elaboração própria a partir das Portarias ministeriais (1990-2004).

* Portarias que se enquadram em mais de uma linha de atuação;

** Leis e Decretos não são contabilizadas no total de documentos do quadro, mas constam a título de informação. 
Com as Portarias GM no. 1.635/02 e SAS no. 728/02, aos pacientes com deficiência mental e autismo passaram ser oferecidos serviços e procedimentos específicos 6 .

Este período consagra a retomada da aceleração da desospitalização e da expansão de serviços extra-hospitalares (Figuras 1 e 2). Por outro lado, é possível falar de certa especialização dos dispositivos assistenciais - como as tipologias de CAPS, e das frentes de cuidado - como a regulamentação voltada para deficiência mental e autismo. Acompanha isso a construção de dispositivos não assistenciais que vêem fortalecer o modelo de cuidado em saúde mental, como o Auxílio-Reabilitação Psicossocial do Programa De Volta Para Casa e os Serviços Residenciais Terapêuticos.

Se no começo da década de 1990 o discurso oficial era mais voltado para a qualificação da assistência psiquiátrica, mais recentemente voltase para a constituição de uma rede de cuidado em saúde mental, logrando o desenho de um novo modelo assistencial (Figura 3).

\section{Considerações finais: reflexões sobre o modelo assistencial em saúde mental}

Se a psiquiatria, assim como outras especialidades envolvidas no tratamento do transtorno mental, assume a dimensão política de seu saber, sua insuficiência, e também a incurabilidade da doença mental ${ }^{3}$, abre-se espaço para olhar o doente como um cidadão de existência complexa, multidimensional, portador de história e construtor de sentidos e valores. Abre-se espaço para buscar o cuidado ao invés da cura. Quanto ao cuidado é pressuposto não ser operado exclusivamente pelo psiquiatra, mas por todo profissional do campo da saúde mental, pelo meio social e pelo próprio paciente. A despeito da incurabilidade da doença, a proposta do cuidado encontra fundamento no entendimento de que é possível produzir saúde. Canguilhem 10 já nos mostrou essa inflexão: saúde e doença não são fenômenos opostos perfeitos se compreendemos a saúde como uma produção cotidiana de mais saúde e por melhores formas de vida.

Sob essa perspectiva, justifica-se, na construção de um modelo assistencial complexo e integral, recorrer tanto a dispositivos assistenciais quanto não assistenciais. Nesse sentido, hoje dispomos de várias possibilidades que visam constituir uma rede articulada

No entanto, como já apontamos, a heterogeneidade dos embasamentos que informam a política de saúde mental brasileira nos impõe certo impasse. Até agora essa política tem se construído em torno da proposta da Declaração de Caracas 6 de "reestruturação" da assistência, configurando o que sugerimos denominar, como recurso didá-

Figura 3

Aspectos diferenciais de cada momento da década expandida 1990 a 2004

1991 - Coordenação de Saúde Mental

1991-1996 - Momento germinativo:

- 5 Ministros

- Articulação inter-níveis - Colegiado de Coordenadores Estaduais

- Abertura de possibilidades:

- Ênfase no processo de desospitalização e qualificação.
1997-1999 - Momento de latência:

- Sem produção normativa

- Atuação do Conselho Nacional de Saúde.

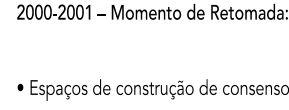

(1)

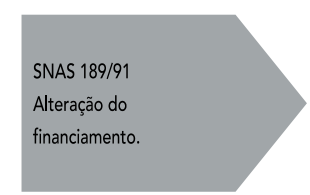

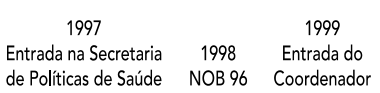

de Políticas de Saúde NOB 96 Coordenador

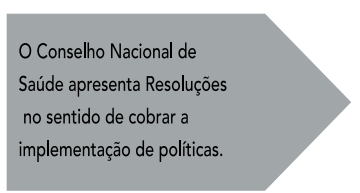

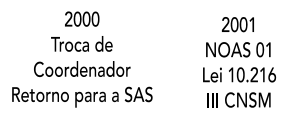

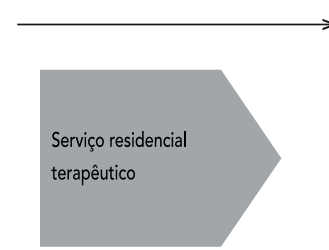

2002-2004 - Momento de Expansão:

- Coordenador estáve

- Estratégia de redução de leitos e avaliação;

- Entrada de recursos estratégicos - mudanças

de modelo;

- Política de expansão com ênfase na

abrangência populacional.

$$
2003
$$

Aprovação da Lei

10.708

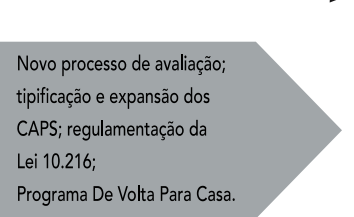

Fonte: Elaboração própria a partir das Portarias ministeriais (1990-2004). 
tico, "aspecto externo" do modelo assistencial, ou seja, aquele que diz respeito à constituição dos serviços enquanto uma rede dinâmica, coesa, articulada e complexa, tanto internamente quanto na relação com a comunidade.

Mas a proposta Basagliana nos impele a refletir sobre o que propomos reconhecer como "aspecto interno" do modelo, aquele voltado para gestão do trabalho de cuidado, para o espaço que os usuários e a comunidade ocupam nessa gestão, para a porosidade do técnico e de sua ação às singularidades espaço-temporais. E para isso o manicômio deve ser destruído, visto que sua existência invalida "o resultado do trabalho do técnico na medida em que ele já é previsivel, em certas condições, e o restringem a um âmbito de ação no qual os próprios 'sucessos terapêuticos' são garantidos (...) pela precisão com que se articula o complexo mecanismo de distribuição de clientela" 4 (p. 257).

O desenho do aspecto interno visa garantir que as formas de cuidado não sejam pré-concebidas, que atendam às especificidades do sujeito singular sem o "respaldo" do hospital psiquiátrico em caso de "fracasso terapêutico". Assim, não deve haver fracasso, mas a necessidade de investir em formas de cuidado mais adequadas, mesmo que estas nasçam e se dissolvam ininterruptamente. Importa que o cuidado seja adequado às necessidades de quem as determina.

Esse modo de olhar internamente corresponderia ao uso das crises como Basaglia ${ }^{4}$ (p. 255) propõe: "os processos de crise e desestabilização que se vão produzindo dentro desses aparatos, nas normas que os regulam e que regulam seu uso, correspondem, para os novos serviços territoriais, a outros tantos espaços de intervenção ainda abertos...".

Isso implica uma forma sistemática de avaliação cotidiana da prestação de cuidado que deve ser integrada com a ação de um órgão propositivo de políticas oficiais - a Coordenação Nacional de Saúde Mental - na construção do modelo assistencial voltado para desinstitucionalização. Fundamento disso é a compreensão de que a formulação de políticas por um nível central não é um processo de mão única, ou pelo menos não deve ser, mas envolve o retorno, envolve a idéia de processo ${ }^{11}$, a ação questionadora e propositiva nesses espaços onde se dá o cuidado. A formulação da política de saúde mental deve estar sempre no gerúndio em qualquer desses espaços ora chamados de níveis de gestão, ora chamados de "ponta". Enfim, devem ocorrer em espaços diferenciados sempre compondo um processo uno.

A constatação mais clara diante da análise dos documentos normativos é o fato de o modelo assistencial em saúde mental ser recém-nasci- do enquanto um conjunto diversificado de dispositivos que contemplem mais que o binômio hospital-ambulatório. A expansão dos CAPS e a criação de financiamento para outras estruturas, tanto assistenciais quanto não assistenciais, são ainda recentes. Seria cedo para fazermos críticas a esse modelo e para concluir se tem ou não funcionado como uma rede complexa e articulada, se não fosse uma das premissas primeiras da proposta da desinstitucionalização: a do questionamento como processo cotidiano de análise do trabalho.

Com a preocupação de fazer acompanhar a maturação desse modelo assistencial de um processo avaliativo são vários os autores dedicados ao tema 12,13, mas Barreto 14 (p. 24) nos alerta coerentemente de que "das avaliações de qualidade não se deve esperar mais do que podem cumprir", e que são desejáveis exatamente pelo que são e não pelo que desejariam cumprir convertendo conceitos em indicadores. Ou seja, há aspectos tradicionalmente apreendidos por pesquisas científicas e de grande interesse administrativo para avaliações qualitativas, mas, no outro pólo, há aspectos mais avessos a sistematizações avaliativas que envolvem entre outras coisas "efemeridades da expressão subjetiva” 14 (p. 27).

A compreensão dessa polaridade permite que identifiquemos o segundo grupo de aspectos como constituinte dos aspectos internos do modelo assistencial. O trabalho de desinstitucionalização não pode remeter apenas ao político, jurídico, teórico-conceitual e sócio-cultural. Não pode esquecer de dar visibilidade e conferir concretude ao técnico-assistencial - atravessado pelas outras dimensões, o que implica diferentes modos de olhar para a organização dos dispositivos assistenciais, externamente e internamente.

As Portarias analisadas mostram que se cumpre a função normativa referente ao aspecto de organização externa dos dispositivos assistenciais. No entanto, também deve ser cotidiano e sistemático o levantamento de perguntas sobre a função da Coordenação Nacional de Saúde Mental. Caberia fazer mais? Quais os limites, inferiores e superiores, do papel da coordenação? Qual tem sido sua atuação na gestão, nos aspectos internos ao modelo assistencial proposto? É função da coordenação atuar nesses aspectos? Qual tem sido a inserção dos dispositivos assistenciais no processo de formulação política e intervenção sobre a coordenação?

O peso da atuação da Coordenação Nacional de Saúde Mental é reflexo não apenas da concepção de qual seria seu papel, mas também do contexto político-ideológico no qual se insere. Assim, é importante pesar o grau de institucionalidade 
da política e o grau de hegemonia do pensamento que a ancora. O enfrentamento de oposições à reforma psiquiátrica e à política de saúde mental brasileira também ajuda a desenhar o perfil de atuação da coordenação. Atualmente, sem dúvida, é centrado em aspectos mais internos, como por exemplo, a constituição da Comissão Revisora da Internação Involuntária. Os aliados desta reforma e desta política também se voltam para a construção de uma agenda diferenciada, preocupada com processos avaliativos.

\section{Resumo}

O artigo analisa as condições da construção da política nacional de saúde mental no Brasil no periodo de 1990 a 2004 com o objetivo de identificar as linhas de atuação priorizadas em cada momento da política. Realiza revisão e análise dos documentos normativos (Portarias) e outros documentos oficiais expedidos pelo Ministério da Saúde relativos à política de saúde mental, formulados a partir de 1990. O estudo pressupõe que esses documentos oferecem subsídios para a compreensão do modelo assistencial implementado. São discutidos quatro momentos da política de saúde mental - germinativo, de latência, de retomada e de expansão - nos quais busca-se identificar os principais elementos norteadores da ação política e suas correlações com o contexto mais geral do Sistema Único de Saúde (SUS). Por fim, o artigo oferece um panorama do modelo assistencial em saúde mental construído, contrapondo-o, numa breve reflexão, ao referencial teórico-ideológico basagliano - referencial este adotado pelo movimento brasileiro pela reforma psiquiátrica - e apontando rumos para uma reflexão acerca da atuação da Coordenação Nacional de Saúde Mental.

Saúde Mental; Política de Saúde; Reforma dos Serviços de Saúde
É certo que o espaço de construção de uma política ultrapassa o perímetro da produção normativa, ultrapassa a oficialidade de uma política de governo expressa em Portarias, e constrói-se em interlocuções mais ou menos formais, mais ou menos perenes, mas certamente concorrentes com este processo. Não obstante, a produção normativa age na interlocução e na configuração tanto do modelo assistencial quanto no cenário de debates e mostra-se um rico recurso de análise, apontando inclusive para a necessidade de uma inflexão na agenda da política de saúde mental.

\section{Colaboradores}

As autoras definiram em parceria a concepção geral e o conteúdo do artigo. A revisão teórica e metodológica foi redigida por C. F. Borges, os resultados e análise da política foram redigidos pelas duas autoras em conjunto, sendo a revisão final realizada por T. W. F. Baptista 


\section{Referências}

1. Resende H. Política de saúde mental no Brasil: uma visão histórica. In: Tundis SA, Costa NR, organizadores. Cidadania e loucura: políticas de saúde mental no Brasil. Petrópolis: Editora Vozes/Rio de Janeiro: ABRASCO; 2001. p. 15-73.

2. Amarante P. Asilos, alienados e alienistas. In: Amarante $\mathrm{P}$, organizador. Psiquiatria social e reforma psiquiátrica. Rio de Janeiro: Editora Fiocruz; 1994. p. 73-83.

3. Amarante P. Loucos pela vida: a trajetória da reforma psiquiátrica no Brasil. Rio de Janeiro: Editora Fiocruz; 1998.

4. Basaglia F. O circuito do controle: do manicômio à descentralização psiquiátrica. In: Amarante $\mathrm{P}$, organizador. Escritos selecionados em saúde mental e reforma psiquiátrica/Franco Basaglia. Rio de Janeiro: Editora Garamond; 2005. p. 237-57.

5. Kalil MEX, organizador. Saúde mental e cidadania no contexto dos sistemas locais de saúde. São Paulo: Editora Hucitec; 1992.

6. Secretaria de Atenção à Saúde, Ministério da Saúde. Legislação em saúde mental: 1990-2004. Brasília: Ministério da Saúde; 2004.

7. Baptista TWF. Políticas de saúde no pós-constituinte: um estudo da política implementada a partir da produção normativa dos Poderes Executivo e Legislativo no Brasil [Tese de Doutorado]. Rio de Janeiro: Instituto de Medicina Social, Universidade do Estado do Rio de Janeiro; 2003.
8. Conselho Nacional de Saúde, Ministério da Saúde. Resolução CNS nº. 272, de 5 de março de 1998. Diário Oficial da União 1998; 1 abr.

9. Levcovitz E, Lima LD, Machado CV. Política de saúde nos anos 90: relações intergovernamentais e papel das normas operacionais básicas. Ciênc Saúde Coletiva 2001; 6:269-91.

10. Canguilhem G. O normal e o patológico. Rio de Janeiro: Editora Forense Universitária; 2002.

11. Abrucio FL. A coordenação federativa no Brasil: a experiência do período FHC e os desafios do governo Lula. Revista de Sociologia e Política 2005; 24:41-67.

12. Onocko-Campos RT, Furtado JP. Entre a saúde coletiva e a saúde mental: um instrumental metodológico para avaliação da rede de Centros de Atenção Psicossocial (CAPS) do Sistema Único de Saúde. Cad Saúde Pública 2006; 22:1053-62.

13. Fidelis P. O desafio da produção de indicadores para avaliação de serviços de saúde mental: um estudo de caso do Centro de Atenção Psicossocial Rubens Corrêa, RJ. In: Amarante P, organizador. Arquivos de saúde mental e atenção psicossocial. Rio de Janeiro: Nau Editora; 2003. p. 89-119.

14. Barreto J. O umbigo da reforma psiquiátrica: cidadania e avaliação de qualidade em saúde mental. Juiz de Fora: Editora da Universidade Federal de Juiz de Fora; 2005.

Recebido em 27/Fev/2007

Versão final reapresentada em 01/Ago/2007

Aprovado em 25/Ago/2007 